\title{
Vitamin D as an adjunct for acute community- acquired pneumonia among infants and children: systematic review and meta-analysis
}

Soumyadeep Bhaumik ${ }^{1 *}$ Zohra Lassi $^{2}$

\author{
Plain language summary
}

Pneumonia is the most important cause of death in children under five years old. Most deaths occurs in children in low- and middle-income countries who have poor nutrition and lower immunity. Standard medical therapy consists of antibiotics and supportive care.

Vitamin $D$ is cheap and known to improve the immune system response against respiratory diseases such as tuberculosis. Previous studies have examined whether vitamin D supplements are useful to prevent pneumonia, but less attention has been paid to the use of vitamin $D$ to aid in the treatment of pneumonia.

This study searched the literature and found three clinical trials of vitamin $D$ as an additional treatment for pneumonia in children. These trials were from India or Afghanistan and included 997 infants and children in total. Taken together, these trials showed no effect of vitamin D cure rates, mortality, time to clinical recovery or duration of hospital stay for pneumonia in children. The quality of evidence is however low.

The authors conclude that current evidence is limited but does not support the use of vitamin D supplements during treatment of pneumonia in children. Further trials are needed on this topic.

\section{Abstract}

Background: Community-acquired pneumonia (CAP) is a major cause of mortality and morbidity among infants and children, particularly in low and middle income countries. Vitamin D, which plays a role in innate as well as adaptive immunity, is a candidate low-cost intervention as an adjunct for treatment of CAP.

Methods: We searched multiple electronic databases as well as grey literature to search for randomised controlled trials (RCTs) on vitamin D as an adjunct in infants and children with CAP. We used the Cochrane methodology for assessing risk of bias and, where adequate data was available, conducted a meta-analysis using a fixed or randomeffects model as applicable. We assessed overall evidence quality using the GRADE approach.

Findings: We screened 272 unique papers and 25 clinical trial registry records and identified three completed and three ongoing trials based on our inclusion criteria. Two completed trials were from India and one from Afghanistan. These three RCTs included a total of 977 participants. Baseline and follow-up vitamin D status was reported in only one RCT. There was no significant effect of vitamin D noted on clinical cure rates (risk ratio (RR) $1.01 ; 95 \%$ confidence interval $(\mathrm{Cl}) 0.91,1.13$; one study, 200 participants, low quality on GRADE), and all-cause mortality (RR 1.01; $95 \% \mathrm{Cl} 0.23$, 4.41; three trials, 977 participants, low quality on GRADE). Pooled analyses was not possible for the outcomes of time to clinical recovery of pneumonia and total duration of hospital stay, but none of the trials which studied them demonstrated any significant effect of vitamin D on these outcomes individually.

Conclusions: There is insufficient evidence available from RCTs to justify the routine use of vitamin D in infants and children with CAP currently and more research is needed to understand several issues related to this.

\footnotetext{
${ }_{1 \text { D Department of International Public Health, Liverpool School of }}$

Tropical Medicine, United Kingdom

${ }^{2}$ Robinson Research Institute, University of Adelaide, Australia

*Author correspondence: drsoumyadeepbhaumik@gmail.com

ORCID: 0000-0002-5350-6334

Licensed under: CC-BY

Received 19-01-2017; accepted 14-06-2017
}

\section{Registration: PROSPERO ID 2014:CRD42014010259}

Keywords: Pneumonia, vitamin D, children, infants, systematic review, meta-analysis 


\section{Introduction}

Worldwide, community acquire pneumonia (CAP) is the leading cause of mortality among under-five children, accounting for approximately 1.3 million deaths annually. ${ }^{[1]}$ Most of these deaths occur in South Asia and Africa where the prevalence of malnutrition among children is high. ${ }^{[2]}$ The consequences of pneumonia are even more severe on account of lower immunity among children with malnutrition. ${ }^{[3]}$ Low-cost interventions for better management of pneumonia, particularly those which can boost the immune response, might hence contribute to decreased mortality rates from pneumonia in children.

The role of vitamin D in immunity and consequently in the pathogenesis, treatment and prevention of human infectious diseases, particularly of the respiratory tract, has come into limelight in the last few decades, although the role of vitamin $D$ in tuberculosis has been postulated for more than a century. ${ }^{[4][5][6][7]}$ The vitamin $D$ receptor (VDR) and CYP27B1 (the enzyme which converts vitamin $D$ into its active form) has been found in macrophages, monocytes, dendritic cells and respiratory epithelial cells, which play a pivotal role in innate as well as adaptive immune responses. ${ }^{[8][9]}$

Vitamin D deficiency has been linked to increased susceptibility to various infectious diseases, pneumonia and tuberculosis being the most prominent among them. The role of vitamin D in preventing infections has been studied in multiple randomised controlled trials (RCTs). Previous systematic reviews which have investigated the role of vitamin D supplementation for prevention of respiratory infections indicate a protective effect of vitamin D. ${ }^{[10][11][12]}$ Vitamin D levels have been correlated to the severity of pneumonia in children in various case-control studies. ${ }^{[13][14]}$ In rickets, which is a very severe form of vitamin $D$ deficiency (leading to even skeletal malformations and calcium deficiency), the risk of respiratory infections in children has been found to be increased. ${ }^{[15][16][17]}$

Given that previous systematic reviews have focused on prevention of pneumonia through vitamin D supplements, and given evidence from observational studies on the link between vitamin D and pneumonia, we set out to systematically review the evidence available from RCTs on the use of vitamin $D$ as an adjunct for treatment of CAP in infants and children.

\section{Methods}

We searched for published and unpublished RCTs on infants and children from 1 month to 5 years of age given vitamin D (in any dose, regimen or route) as an adjunct to standard therapy (as defined by trial authors) for acute CAP and compared to placebo (or nothing). All aetiologies of pneumonia (except aspiration pneumonia) and all degrees of severity were included. The protocol for this systematic review and meta-analysis has been registered with PROSPERO 2014:CRD42014010259. The systematic review followed the PRISMA guidelines. ${ }^{[18]}$

We only included trials which had used either of the two diagnostic criteria for acute CAP as given below:

1. Diagnosis of acute CAP by a physician on the basis of clinical examination and/or radiological features; or,

2. History of cough or respiratory distress with a respiratory rate above the World Health Organization (WHO) defined age-specific respiratory rate of $>50$ breaths per minute for children aged two to 11 months, or respiratory rate $>40$ breaths per minute for children aged 12 to 59 months); and either documented fever of > $38.33^{\circ} \mathrm{C}\left(101^{\circ} \mathrm{F}\right)$ or chest in-drawing. ${ }^{[19]}$

Trials on patients with congenital abnormalities, rickets, and protein-energy malnutrition or proven fungal pneumonia were excluded. We also excluded trials in which vitamin D was administered along with other vitamins or supplements. The review included all papers irrespective of language or publication status.

The primary outcomes we considered were:

1. Clinical cure rate, which was defined as clinical recovery (that is no fever, no tachypnoea and no chest indrawing) by the end of treatment;

2. Time to clinical recovery of pneumonia;

3. Time to radiological resolution; and

4. All-cause mortality at end of follow-up (as defined by trial authors).

The secondary outcomes we considered were:

1. Total duration (in hours) of hospital stay (time from randomisation to discharge);

2. Requirement of any additional interventions like mechanical ventilation, corticosteroids, vasopressor agents, or anything else;

3. Rates of any of the following complications of pneumonia: parapneumonic effusions and empyema, necrotising pneumonia, septicaemia and metastatic infection. 
We searched for trials in four electronic databases adopting the following PubMed search strategy "(((vitamin D OR Cholecalciferol OR Ergocalciferol OR calcitriol))) AND (pneumon* OR bronchopneumon*)" without restricting for language or date:

1. PubMed (search updated to 24 January 2017)

2. Cochrane Central Register of Controlled Trials (CENTRAL) (search updated to 24 January 2017)

3. CINAHL (searched updated to 24 January 2017)

4. Global Health (searched 20 June 2016)

We searched two clinical trial registries (ClinicalTrials.gov and the WHO International Clinical Trials Registry Platform (ICTRP)) using the following search strategy "Pneumonia AND (vitamin D OR cholecalciferol OR ergocalciferol OR calcitriol)" in February 2016. We also searched for grey literature by contacting researchers and searching abstracts of scientific meetings (Supplementary Data File 1) and references of included trials found by other methods.

Two review authors independently screened all the search results initially for consideration of inclusion as per eligibility criteria based on their titles and abstracts. After the initial screening full texts were obtained and assessment for inclusion and extraction was done by two authors independently. The risk of bias assessment on each study was independently conducted by two authors according to the methodology laid down in the Cochrane Handbook for Systematic Reviews of Interventions. ${ }^{[20]}$ Any discrepancies were resolved by consensus.

We used risk ratios (RR) for dichotomous data and mean difference (MD) for continuous data with 95\% confidence interval $(\mathrm{Cl})$ using Review Manager 5 software. ${ }^{[21]}$ Where data was sufficient, we combined data using intention-to-treat (ITT) analysis and calculated a summary statistic for each outcome by a meta-analysis. The statistical heterogeneity was determined by a combination of visual inspection of graphs of RRs as well as using the $\mathrm{I}^{2}$ statistic, and the Chi ${ }^{2}$ test. ${ }^{[20]}$

Where appropriate we conducted meta-analyses. We used a used a random-effects model if studies were statistically heterogeneous, otherwise we used a fixed-effect model. When random-effects model was used, we additionally conducted a sensitivity check using a fixedeffects model to understand differences in results. ${ }^{[20]}$

We had planned to conduct a sub-group analysis if sufficient number of trials were found for several parameters (severity of pneumonia, dosage, frequency, type and route of antibiotics used and dosage, frequency and route of vitamin $D$ supplementation) but this was not possible. We summarised the main findings of the review in the summary of findings table using the GRADE approach. ${ }^{[22]}$

\section{Results}

\section{Characteristics of the included RCTs}

The literature search identified a total of 365 papers and 25 clinical registry records (PRISMA Diagram Figure 1), of which six trials met the eligibility criteria, of which three have been completed ${ }^{[23][24][25]}$ and three are yet to be published (NCT02054182, NCT02185196, NCT02936895).

The main features of the completed trials are summarised in Table 1. The ongoing trials are being conducted in South Africa, Bangladesh and Iran (the latter completed as per record but not yet published). The characteristics of these trials as evident from the clinical trial registries are presented in Table 2 . Reasons for excluding other trials are documented in Supplementary Data File 1. The PRISMA compliance checklist is presented in Supplementary Data File 2.

The completed trials were from India ${ }^{[23][24]}$ and Afghanistan ${ }^{[25]}$. These trials enrolled children of different age groups, severity of pneumonia, and varied in terms of the dosage and duration of vitamin $D$ supplementation. Both studies from India included only children with severe pneumonia but while the earlier study ${ }^{[23]}$ included children of 2 months to 5 years, the recent trial[ ${ }^{[24]}$ included children in the age group 6 months to 5 years of age. The definition of severe pneumonia was different in the two Indian trials. In one tria|[ ${ }^{[23]}$ severe pneumonia was defined as those with pneumonia with either chest in-drawing or at least one of the three danger signs (inability to feed, lethargy, and cyanosis). The 2016 Indian trial defined severe pneumonia as the presence of lower chest in-drawing with cough and difficult breathing. ${ }^{[24]}$ Both the Indian trials ${ }^{[23][24]}$ excluded children with rickets, severe acute malnutrition, asthma, hypertension, complicated pneumonia or severe illnesses (Table 1). The trial from Afghanistan ${ }^{[25]}$ included children of 1 week to 3 years of age presenting with non-severe, severe and very severe pneumonia. The trial from Afghanistan $^{[25]}$ excluded children with rickets whereas five of the included children in the Indian trial had rickets ( 2 in vitamin $D$ and 3 in placebo group).

The earlier Indian trial used vitamin D [more specifically vitamin D3 or cholecalciferol, dr. P. Gupta, personal communication] (1000 IU to children less than a year and 2000 IU to children between 1-5 years of age) for five days in the intervention $\operatorname{arm}^{[23]}$, while the recent Indian 
trial used a much higher but single dose of 100,000 IU of oral cholecalciferol. ${ }^{[24]}$ In the trial from Afghanistan a single dose of $10,000 \mathrm{IU}$ of Vitamin D was given orally in the intervention arm. ${ }^{[25]}$ Baseline and follow-up vitamin $D$ status was not determined in the earlier two $\mathrm{RCTs} s^{[25][23]}$ but the recent Indian trial[ ${ }^{[24]}$ has measured it.

The completed trials were judged to be low risk of bias for most parameters except some. Figure 2 provides a graphical summary of the risk of bias and the basis for these assessments is provided in Table 3.

\section{Clinical cure rates}

Only one trial[ ${ }^{[23]}$ reported this outcome and found no effect of Vitamin D as an adjunct on clinical cure rates (RR $1.01 ; 95 \% \mathrm{Cl} 0.91,1.13$ ) (Figure 3).

\section{Time-to-clinical recovery of pneumonia}

All trials reported this outcome and individually none of the trials found any significant difference in the time to clinical recovery of pneumonia in between those given vitamin D and those given placebos. In the 2012 trial from In $\mathrm{dia}^{[23]}$, the median time of recovery in the vitamin D group was 72 hours (standard error (SE) 4.5, 95\% $\mathrm{Cl} 48,96$ hours) and 64 hours (SE, 95\% Cl 48, 88 hours) in the placebo group ( $P$ 0.33). The trial from Afghani$\operatorname{stan}^{[25]}$ found that mean time-to-clinical recovery in vitamin $D$ group was $4.74 \pm 2.22$ days and in placebo group was $4.98 \pm 2.89$ days (P 0.17). The 2016 trial from In$\mathrm{dia}^{[24]}$ found no statistically significant difference for time to complete recovery from pneumonia between the vitamin D and placebo arm (Log Rank Chi² P 0.382).

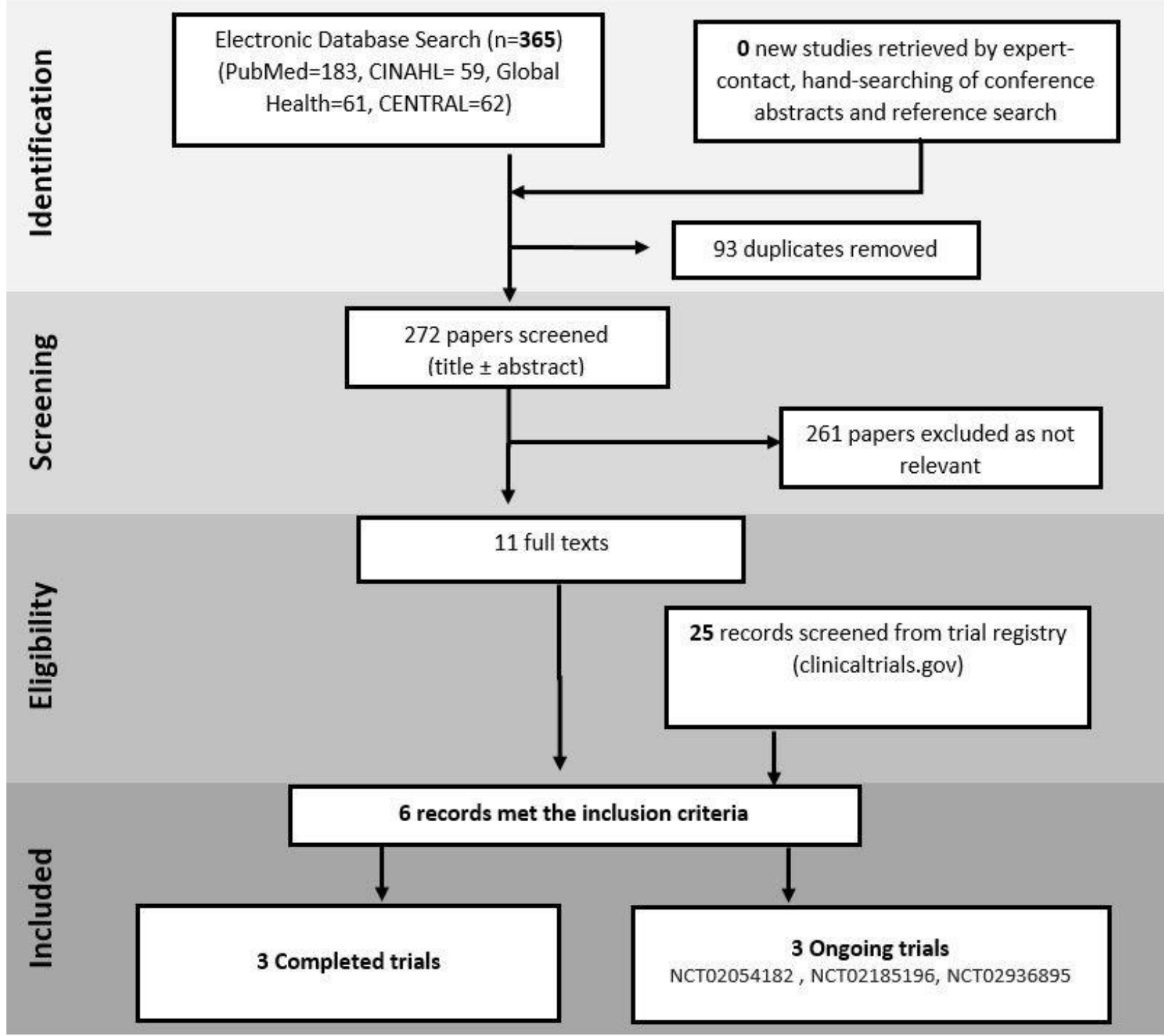

Figure 1 | PRISMA flowchart showing the inclusion of studies. 
Table 1 | Characteristics of completed trials

\begin{tabular}{|c|c|c|c|}
\hline & Gupta et al. 2016 & Choudhary and Gupta 2012 & Manaseki-Holland 2010 \\
\hline Country and setting & India; tertiary care hospital & India; tertiary care hospital & Kabul, Afghanistan; outpatient clinic \\
\hline Participants' age & $\begin{array}{l}\text { Aged } 6 \text { months to } 5 \text { years with the median (IQR) } \\
\text { age of enrolled children ( } 226(69 \cdot 8 \%) \text { boys) was } \\
12(7,20) \text { months. }\end{array}$ & $\begin{array}{l}2 \text { months to } 5 \text { years with a mean (SD) of } 13.9 \\
\text { (11.7) months }\end{array}$ & $\begin{array}{l}1 \text { week to } 3 \text { years of age with a mean (SD) age of } \\
13.13(9.1) \text { months in vitamin D group and } 13.19(9.2) \\
\text { months in placebo group. }\end{array}$ \\
\hline
\end{tabular}

\begin{tabular}{l|l} 
Inclusion & $\begin{array}{l}\text { Children aged } 6 \text { months to } 5 \text { years with a clinical } \\
\text { diagnosis of severe pneumonia. It was ensured } \\
\text { that the family was staying within a } 10 \mathrm{~km} \text { radius } \\
\text { of the hospital. }\end{array}$
\end{tabular}

Children with a clinical diagnosis of severe pneumonia, presenting to paediatric emergency department.

Definition of Pneumonia: Children with fever, cough, tachypnoea and crepitation were diagnosed with pneumonia.

Definition of Tachypnoea: Tachypnoea was defined as respiratory rate $\geq 50 / \mathrm{min}$ in children between 2-12 months and $\geq 40 / \mathrm{min}$ in $1-5$ years age group.

Definition of Severe Pneumonia: Those with pneumonia and either chest in drawing or at least one other danger sign (inability to feed,

lethargy, and cyanosis) were diagnosed as having severe pneumonia.

Children with severe wasting (weight for height $<3 S D$ ), chronic illnesses, previous history of vitamin D intake over last 4 weeks, and known asthmatics were excluded.

gestive rachitic rosary, bow legs or knock knee), severe acute malnutrition, asthma, hypertension, complicated pneumonia (lung abscess, pleural effusion, empyema) or illness severe enough to require ventilation, chronic respiratory disease, heart disease, renal or hepatic insufficiency, neurological illness resulting in abnormalities of muscle tone/power, and known immunodeficiency were excluded. Children having received vitamin D or calcium supplements within four
Children diagnosed clinically with 'pneumonia' (nonsevere or severe) at the local Maywand Teaching Hospital were eligible for inclusion in the trial.

Definition of Pneumonia: (i) Age-specific tachypnoea (>60/min if $<2$ months; $>50 /$ min if $2-11$ months; $>40$ if 12- 24 months) and (ii) absence of wheeze (with or without fever).

Definition of Severe pneumonia: above-mentioned criteria of pneumonia plus chest in drawing. Definition of Very severe pneumonia: criteria of pneumonia plus at least one of the danger signs (central cyanosis, severe respiratory distress [head nodding, nasal flaring, grunting], inability to drink, convulsions, vomiting).

Definition of Fever: Axillary temperature $>37.50^{\circ} \mathrm{C}$ (age 1 week-3 months) or $>38.0^{\circ} \mathrm{C}$ ( $2-23$ months).

Children who had clinical signs of rickets or were known to have received high-dose vitamin D treatment in the past 3 months (one child) had severe vomiting (one child) or pronounced wheeze (10 children) were excluded from the study. (Children who developed wheeze after enrolment were not excluded.). Thirteen children with very severe pneumonias and nine children with other severe illnesses (meningitis, heart or renal disorders, measles, severe malnutrition and suspected tuberculosis) were also excluded. 


\begin{tabular}{|c|c|c|c|}
\hline & Gupta et al. 2016 & Choudhary and Gupta 2012 & Manaseki-Holland 2010 \\
\hline Exclusion (cont.) & $\begin{array}{l}\text { weeks prior to enrolment, those diagnosed with } \\
\text { hypercalcemia or allergy to vitamin } D \text {, or immun- } \\
\text { ized with pneumococcal/flu vaccine were also } \\
\text { excluded. }\end{array}$ & & \\
\hline Intervention & $\begin{array}{l}\text { Vitamin D ( } n=162 \text { ) } \\
\text { Dosage: } 100 \text { '000 IU of vitamin D3 (cholecalcif- } \\
\text { erol) } \\
\text { Delivery: The drug/placebo was dispensed in } \\
\text { milk. } \\
\text { Route: Oral. Those unable to take orally were } \\
\text { given the drug by nasogastric tube. } \\
\text { Frequency: Single dose }\end{array}$ & $\begin{array}{l}\text { Vitamin D ( } n=100 \text { ) } \\
\text { Dosage: } 1000 \text { IU of vitamin D3 to children < one } \\
\text { year of age and } 2000 \text { IU to children between 1-5 } \\
\text { years of age. } \\
\text { Delivery: The drug/placebo was dispensed in } \\
\text { milk. } \\
\text { Route: Oral. Those unable to take orally were } \\
\text { given the drug by nasogastric tube. } \\
\text { Frequency: First dose within four hours of admis- } \\
\text { sion. This was followed by once-a-day dosing. } \\
\text { Duration: } 5 \text { days }\end{array}$ & $\begin{array}{l}\text { Vitamin D3 }(\mathrm{n}=224) \\
\text { Dosage: } 10^{\prime} 000 \mathrm{IU} \\
\text { Delivery: The drug/placebo was dispensed in olive oil. } \\
\text { Route: Oral. } \\
\text { Frequency: Single dose }\end{array}$ \\
\hline Control & Placebo $(n=162)$ & Placebo $(n=100)$ & Placebo $(n=229)$ \\
\hline Other therapies & $\begin{array}{l}\text { Antibiotics were administered for severe pneu- } \\
\text { monia as per the guidelines of the Indian Acad- } \\
\text { emy of Pediatrics. } \\
\text { Hydration was maintained and intravenous fluids } \\
\text { were administered if oral intake was poor. Oxy- } \\
\text { gen was provided with a face mask or oxygen } \\
\text { hood, if the child was having marked respiratory } \\
\text { distress, signs of hypoxia, or oxygen desatura- } \\
\text { tion. The child was nebulized with salbutamol if } \\
\text { there was evidence of bronchospasm (presence } \\
\text { of wheeze) or fast breathing with past history of } \\
\text { nebulization. }\end{array}$ & $\begin{array}{l}\text { Both the groups received antibiotics as per In- } \\
\text { dian Academy of Paediatrics (IAP) guidelines and } \\
\text { supportive care (oxygen, intravenous fluids and } \\
\text { monitoring). Children with associated wheezing } \\
\text { received salbutamol nebulization twice at an in- } \\
\text { terval of } 20 \text { minutes. }\end{array}$ & $\begin{array}{l}\text { Children were treated with antibiotic according to the } \\
\text { national pneumonia treatment protocol [based upon } \\
\text { Integrated Management of Childhood illnesses (IMCI) } \\
\text { guidelines] }\end{array}$ \\
\hline
\end{tabular}




\section{Outcomes reported}

and their definitions
Reclassified from severe pneumonia to pneumonia: when lower chest in drawing disappeared (whereas fast breathing persisted), and remained absent for next 24 hours.

Discharged: when fever and fast breathing were absent for at least 24 hours.

Recurrence: if the child remained free of symptoms of cough or fast breathing for at least seven days following completion of the course of antibiotic therapy as per protocol for the previous episode of pneumonia.

Approximately $80 \%$ of the enrolled children had wheeze, and $98 \%$ has crepitation

Comments

Funding
Time to resolution of severe pneumonia: Reso-

lution of severe pneumonia was considered

when lower chest retraction and the danger

signs (inability to feed, lethargy, cyanosis or hy-

poxia) were no longer present.

Duration of hospitalization: The duration of hospitalization was defined as the time (in hrs) between study enrolment and discharge.

Time to resolution of tachypnoea: respiratory rate cut off for severe pneumonia as per age.

Time to resolution of chest retractions.

Time to resolution of Hypoxia

Time to resolution of Fever: axillary temperature $<37.5$ 으

Time to resolution of inability to feed: oral feeding had resumed, for a minimum period of 24 hours.

Discharge from Hospital: The patient was considered fit for discharge when he/she was afebrile (axillary temperature $<37.5^{\circ} \mathrm{C}$ ), tachypnoea had subsided, there were no chest in drawings, and oral feeding had resumed, for a minimum period of 24 hours.

5 children had clinical evidence of rickets and they were given a mega dose of vitamin $D$

$(600,000 \mathrm{IU})$ at the time of discharge. (rickets; 2 in vitamin $\mathrm{D}$ and 3 in placebo group). $33.5 \%$ of the enrolled children had wheeze. $30 \%$ of the children in intervention and $33 \%$ of the children in placebo arm had past history of pneumonia.

Indian Council of Medical Research, New Delhi. None

The drug and placebo used in the study were provided by Zuventus Healthcare Ltd. India.
Recovery: For two consecutive days, respiratory rate $<40 / \mathrm{min}$, no danger signs or subcostal recession, and no fever.

Failure to treat: No reduction in the resting respiratory rate over a $72 \mathrm{~h}$ period compared to that detected at enrolment after allowing for a variability of \pm 5 breaths / $\mathrm{min}$ of the baseline respiratory rate Repeat episodes of pneumonia: An episode of pneumonia 14 days after the last day of illness of the previous episode of pneumonia

\section{/}

The study was funded by the New Zealand Aid Cooperation. 
Table 2 | Characteristics of ongoing trials

\begin{tabular}{|c|c|c|c|}
\hline & NCT02054182 & NCT02185196 & NCT02936895 \\
\hline Study design & $\mathrm{RCT}$ & $\mathrm{RCT}$ & $\mathrm{RCT}$ \\
\hline Country and setting & South Africa & Bangladesh & Iran \\
\hline Inclusion criteria & $\begin{array}{l}\text { All children age } 1 \text { month }-5 \text { years, admitted in the } \\
\text { paediatric unit, with an acute lower respiratory tract } \\
\text { infection i.e. bronchiolitis and/or pneumonia }\end{array}$ & $\begin{array}{l}\text { Children aged 3- } 59 \text { months with severe pneumo- } \\
\text { nia(clinically diagnosed) with or without diarrhea. }\end{array}$ & $\begin{array}{l}\text { Children aged } 2 \text { months to } 6 \text { years with } \\
\text { definite diagnoses of pneumonia }\end{array}$ \\
\hline Exclusion criteria & $\begin{array}{l}\text { Children whose caregivers decline participation in the } \\
\text { study. Children with co-morbid chronic respiratory } \\
\text { condition(s). Children who have received vitamin D } \\
\text { supplementation in the past } 30 \text { days. }\end{array}$ & $\begin{array}{l}\text { Children who have received vitamin D or calcium sup- } \\
\text { plements within last } 4 \text { weeks, } \\
\text { Known to have hypercalcemia or allergy to vitamin D } \\
\text { Congenital heart disease } \\
\text { Known case of tuberculosis } \\
\text { Renal or hepatic insufficiency } \\
\text { Critically ill children, requiring ICU care, such as those } \\
\text { with septic shock or cardia arrest or apnoea } \\
\text { Any children diagnosed to have hypernatremia during } \\
\text { the main phase of the study }\end{array}$ & $\begin{array}{l}\text { Immunocompromised patients } \\
\text { Airway hypersensitivity or asthma } \\
\text { Allergies } \\
\text { Nasal polyps } \\
\text { Using inhaled medications to one month } \\
\text { prior to the study } \\
\text { Receiving high doses of vitamin D }\end{array}$ \\
\hline Intervention & $\begin{array}{l}\text { Vitamin D ( } n=160) \\
\text { Dosage: } 2500 \text { IU } \\
\text { Route: oral } \\
\text { Frequency: Daily } \\
\text { Duration: From enrolment to discharge }\end{array}$ & $\begin{array}{l}\text { Vitamin D3 ( } n=175 \text { ) } \\
\text { Dosage: } 20 \text { '000 IU in children }<6 \text { month ; } 50 \text { '000 IU in } \\
\text { children } 6-12 \text { month ; } 100 \text { '000 IU in children } 13-19 \\
\text { months on first day and thereafter } 10^{\prime} 000 \text { IU for next } 4 \\
\text { days } \\
\text { Route: Oral } \\
\text { Duration: Single dose }\end{array}$ & $\begin{array}{l}\text { Vitamin D3 }(n=50) \\
\text { Dosage: } 50,000 \text { IU per day } \\
\text { Route: Oral } \\
\text { Duration: for } 2 \text { days }\end{array}$ \\
\hline Control & Placebo ( $n=160)$ & Placebo-Miglyol-oil ( $n=175)$ & Placebo $(n=50)$ \\
\hline Other therapies & Standard therapy & Standard antibiotic and other supportive therapy & Not mentioned \\
\hline Primary outcomes & $\begin{array}{l}\text { Comparison of change from baseline in modified Res- } \\
\text { piratory Distress Assessment Instrument score at hos- } \\
\text { pital discharge }\end{array}$ & Time to recover from severe pneumonia & $\begin{array}{l}\text { Respiratory Index of Severity in Children } \\
\text { (RISC) score }\end{array}$ \\
\hline
\end{tabular}


NCT02054182

\section{Secondary outcomes}

Comparison of duration of hospitalization: from the day of admission to the day the child is assessed and deemed fit for discharge by the attending physician
NCT02185196

Duration of hospitalisation

Time taken for normalisation of temperature

Time taken for normalisation of respiratory rate

Time taken for recovery from chest in drawing

Time taken for oxygen saturation to normalise

Time taken for normalisation of child feeding

Proportion of children who will develop new episode

of pneumonia during 12 months of follow-up

Recruiting (August 2016)

\section{NCT02936895}

Duration of hospitalisation

Completed (October 2016) 
Table 3 | Rationale for risk of bias of included trials

\begin{tabular}{|c|c|c|c|}
\hline Risk of bias domain & Gupta et al. 2016 & Choudhary \& Gupta 2012 & Manaseki-Holland 2010 \\
\hline $\begin{array}{l}\text { Random sequence gen- } \\
\text { eration (selection bias) }\end{array}$ & $\begin{array}{l}\text { Low risk } \\
\text { "Eligible children were randomized using } \\
\text { computer-generated block randomization" }\end{array}$ & $\begin{array}{l}\text { Low risk } \\
\text { "Computer generated random number table." Authors } \\
\text { were not involved with the randomization process }\end{array}$ & $\begin{array}{l}\text { Low risk } \\
\text { "random number sequence generated in an Excel } \\
\text { spreadsheet with no restrictions" }\end{array}$ \\
\hline $\begin{array}{l}\text { Allocation concealment } \\
\text { (selection bias) }\end{array}$ & $\begin{array}{l}\text { Low risk } \\
\text { "The allocation was further concealed by } \\
\text { using sealed opaque envelopes" }\end{array}$ & $\begin{array}{l}\text { Low risk } \\
\text { "Allocation concealment was done by sealed envelope } \\
\text { Technique" }\end{array}$ & $\begin{array}{l}\text { Low risk } \\
\text { "...blinded doctors choosing the next syringe with a } \\
\text { randomisation code." }\end{array}$ \\
\hline $\begin{array}{l}\text { Blinding of participants } \\
\text { and personnel (perfor- } \\
\text { mance bias) }\end{array}$ & $\begin{array}{l}\text { Low risk } \\
\text { "None of the investigators, study staff, and } \\
\text { participants was aware of the drug or pla- } \\
\text { cebo being dispensed." }\end{array}$ & $\begin{array}{l}\text { Low risk } \\
\text { "double blind"; "Both the caretaker and subject were } \\
\text { blind regarding the content of the drug been given" }\end{array}$ & $\begin{array}{l}\text { Low risk } \\
\text { "Double blind"; "Placebo (Containing olive oil alone) } \\
\text { and vitamin D syringes looked the same and the con- } \\
\text { tents tasted the same. None of the investigators, staff } \\
\text { in Kabul and caretakers of children were aware of the } \\
\text { study groups." }\end{array}$ \\
\hline $\begin{array}{l}\text { Blinding of outcome as- } \\
\text { sessment (detection } \\
\text { bias) }\end{array}$ & $\begin{array}{l}\text { Low risk } \\
\text { "None of the investigators, study staff, and } \\
\text { participants was aware of the drug or pla- } \\
\text { cebo being dispensed." }\end{array}$ & $\begin{array}{l}\text { Low risk } \\
\text { "Both the caretaker and subject were blind regarding } \\
\text { the content of the drug been given"; "The code key } \\
\text { was opened only after the intervention, data collec- } \\
\text { tion; follow up and tabulation were completed." }\end{array}$ & $\begin{array}{l}\text { Unclear risk } \\
\text { Insufficient information to permit judgement. Trial au- } \\
\text { thor could not be contacted for further information. }\end{array}$ \\
\hline $\begin{array}{l}\text { Incomplete outcome } \\
\text { data (attrition bias) }\end{array}$ & $\begin{array}{l}\text { Low risk } \\
156 / 162(3.7 \%) \text { in intervention arm and } \\
158 / 162(2.5 \%) \text { in control arm completed } \\
\text { the study. Reasons for loss to follow-up } \\
\text { were almost similar across the groups. }\end{array}$ & $\begin{array}{l}\text { High risk } \\
\text { "A total of } 7 \text { children could not complete the study as } \\
\text { parents left against medical advice. There was no dif- } \\
\text { ference between the two groups in the proportion of } \\
\text { children who improved." Comment: Figure } 1 \text { in the } \\
\text { study does not detail this information. No further in- } \\
\text { formation provided on contact with trial author }\end{array}$ & $\begin{array}{l}\text { Low risk } \\
204 / 224=8.9 \% \text { in Vitamin D group and } 211 / 229= \\
7.9 \% \text { from placebo group were loss to follow up and } \\
\text { reasons were almost similar. }\end{array}$ \\
\hline $\begin{array}{l}\text { Selective reporting (re- } \\
\text { porting bias) }\end{array}$ & $\begin{array}{l}\text { Low risk } \\
\text { Outcomes are reported as mentioned in } \\
\text { the objective and trial registry. }\end{array}$ & $\begin{array}{l}\text { Low Risk } \\
\text { All outcomes are reported as mentioned in the meth- } \\
\text { ods section. No trial registration was done. }\end{array}$ & $\begin{array}{l}\text { Low risk } \\
\text { Outcomes are reported as mentioned in the objective } \\
\text { and trial registry. }\end{array}$ \\
\hline Other bias & $\begin{array}{l}\text { Low risk } \\
\text { Trial is registered CTRI/2013/01/003317. } \\
\text { Funding: Indian Council of Medical Re- } \\
\text { search, New Delhi. }\end{array}$ & $\begin{array}{l}\text { Unclear Risk } \\
\text { Trial was not registered and no protocol published. } \\
\text { Funding: None. }\end{array}$ & $\begin{array}{l}\text { Low risk } \\
\text { Trial is registered. ISRCTN61245920. Funding: New } \\
\text { Zealand Aid Cooperation. }\end{array}$ \\
\hline
\end{tabular}


We could not pool the results from these studies as it is not appropriate to analyse time-to-event data by using methods for pooling continuous outcomes (using mean or median) since the relevant time is known only for those participants who had the event. Individual patient data meta-analyses should be conducted in such a scenario but this was not possible since patient-level data from all three trials was not available.

\section{All-cause mortality}

All three trials reported all-cause mortality, but these trials were heavily underpowered for this outcome with only three events in the vitamin $D$ and three events in the placebo group in all the three trials together. Overall, children with vitamin D supplementation had a nonsignificant 1.01 risk of death ratio compared to children with no supplementation (RR 1.01; 95\% Cl 0.23, 4.41; three trials, 977 participants, Figure 4 and Table 4). A fixed effects model was used since no heterogeneity was detected ( $\mathrm{I}^{2}=0 \%$ and $\mathrm{Chi}^{2}$ non-significant).

\section{Total duration of hospital stay}

Both the Indian trials ${ }^{[23][24]}$ reported this outcome. While the median duration of hospitalization was longer, but statistically non-significant in the vitamin D group compared to the placebo group in the 2012 Indian trial (112 hours (interquartile range (IQR) 96-136) versus 104 hours (IQR 88-128) (P 0.29)), the mean duration of hospital stay in the 2016 Indian trial ${ }^{[24]}$ (in hours) was shorter, but statistically non-significant between the vitamin D group (104.7 \pm 37.9$)$ and the placebo group $(109.4 \pm 46.0)$. We could not pool the results from the studies as it is not appropriate to analyse time-to-event data by using methods for pooling continuous outcomes (using mean or median) since the relevant time is known only for those participants who had the event. Individual patient data meta-analyses was not possible since patient-level data from all three trials was not available.

\section{Time to radiological resolution}

None of the trials reported any data on the outcomes of time to radiological resolution, requirement of any additional interventions and rates of complications.

\section{Safety outcomes}

The earlier trials ${ }^{[23][25]}$ did not report on any safety outcomes e.g. incidence of hypercalcemia but the recent trial from India ${ }^{[24]}$ reported that serious adverse events were similar across vitamin $D(12.2 \%)$ and placebo (12.6\%) groups.

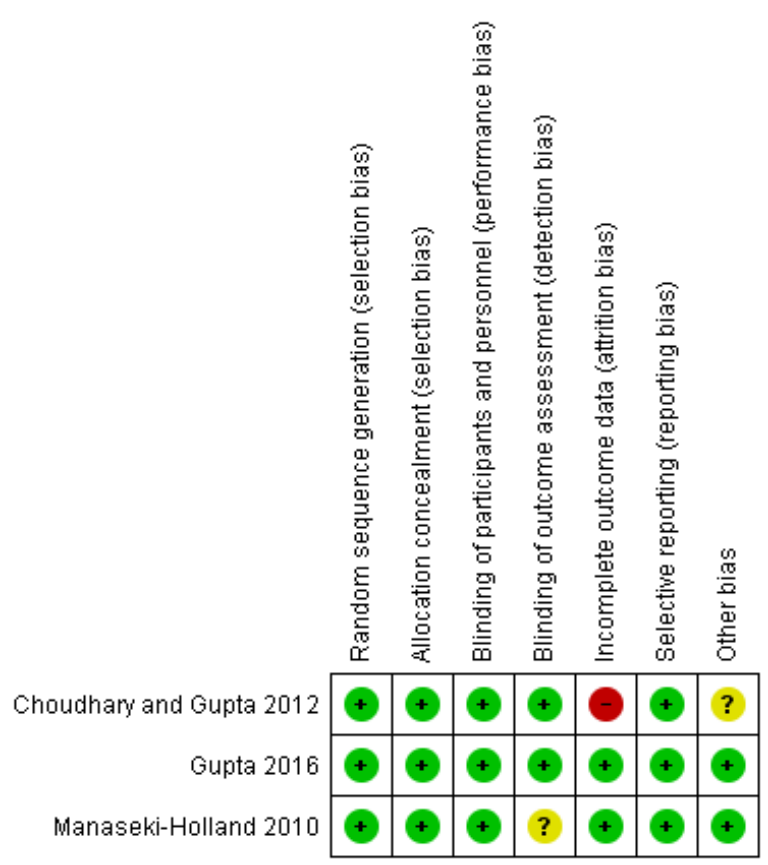

Figure 2 | Risk of bias summary.

\section{Summary of findings}

The GRADE approach was used to summarise the findings and rate the quality of evidence. The quality of evidence was low for the result that vitamin $D$ has no effect on both clinical cure rates and all-cause mortality. A GRADE rating of low implies future research is very likely to change the estimate. Pooling of results was not possible for the other outcomes of time to clinical recovery of pneumonia and time to total duration of hospital stay because individual patient data was not available. However, the results for these outcomes individually for the study also show no statistically significant effect of vitamin $D$ for these outcomes.

\section{Discussion}

\section{Summary of main results}

The results of the three completed trials, all conducted in an in-hospital setting in South Asia, are insufficient to permit any judgement on the clinical effect of vitamin $D$ as an adjunctive treatment for CAP. We found low quality evidence that vitamin $D$ had no effect on clinical cure rates and all-cause mortality in children with CAP. No statistically significant effect was found in any of the studies which reported total duration of hospital stay or time to clinical recovery. 


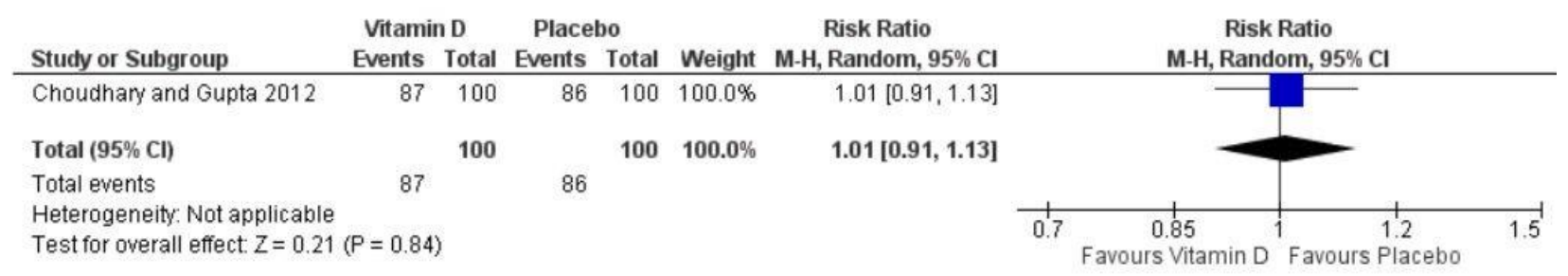

Figure 3 | Forest plot for Clinical Cure Rates: Vitamin D versus Placebo

\section{Strengths and limitations of the systematic review}

This systematic review has used explicit, pre-specified methods in the process and we have searched for RCTs in multiple electronic databases and also by other methods. We believe that no relevant trials have been missed.

Assessment of publication bias, through funnel plots could not be done because of the small number of studies found. The earlier trial from India ${ }^{[23]}$ which we had included in the systematic review had included 5 participants with rickets, which is contrary to the eligibility criteria as per our protocol. However, considering the paucity of evidence and that those with rickets were divided almost equally in the two randomisation arms (2 in vitamin $D$ and 3 in placebo) in the trial, we decided to include this trial in the full systematic review.

\section{Research in context}

A recent Cochrane Review ${ }^{[26]}$ on preventive use of vitamin $D$ for infectious diseases in under-five children found no evidence to support the use of vitamin $D$ for prevention of pneumonia. Contrary to this, an individual patient data meta-analysis published in February 2017 reported that vitamin D prevented acute respiratory infections and "reduced the risk of acute respiratory tract infection among all participants". ${ }^{[12]}$ However, post-publication, the methodology of the study has been debated in the article's rapid responses. The use of vitamin $D$ as an adjunct for treatment during pneumonia for children, we believe is a different research question from the preventive aspects of vitamin $D$. The use of vitamin D for infectious disease prevention has been an active area of research and scores of clinical trials and systematic reviews are already available addressing this topic. We found no evidence of benefit for the use of vitamin $D$ as an adjunct during treatment of pneumonia but the quality of evidence for this is low.

\section{Implications for practice and research}

Current available evidence is insufficient to justify the use of vitamin D as an adjunct therapy to antibiotics and standard respiratory support in CAP among infants and children. Data from observational studies have indicated that vitamin D insufficiency is related to disease severity and prognosis ${ }^{[17][27][28]}$ but the results of our systematic review indicate that current evidence from RCTs does not support any change in practice. There is a need to conduct more placebo-controlled double blinded RCTs with adequate sample size, and appropriate dosage (discussed further below) for evaluating the safety and efficacy of vitamin D as an adjunct to antibiotics for childhood pneumonia of varying severity. Three more RCTs are already underway. However small trials like the trial from Iran (NCT02936895), which is yet to be published and uses composite severity scores as a primary outcome, is unlikely to contribute to the understanding of vitamin D in CAP.

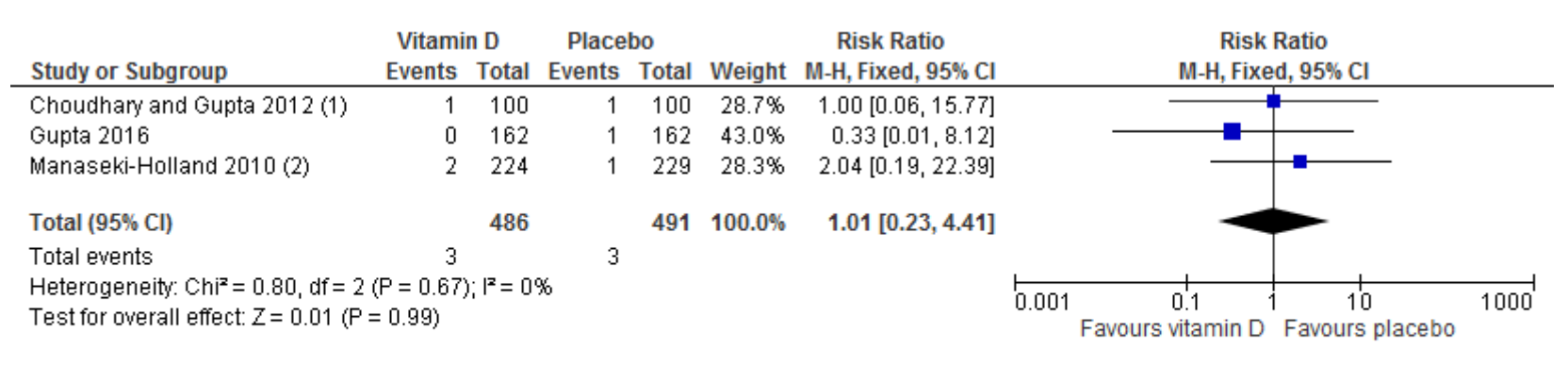

Footnotes

(1) Fast breathing and either chest in drawing or at least one other danger sign (inability to feed, lethargy, and cyanosis)

(2) Children with Fast breathing and Chest in drawing

Figure 4 | Forest plot for all cause-mortality: vitamin D versus placebo. 
Table 4 | GRADE Summary of Findings Table.

\section{Vitamin D for Community Acquired Pneumonia in infants and children under five years of age}

Patient or population: infants and children upto five years of age

Settings: Inpatient Department of Hospital in South Asia

Intervention: Vitamin D

\begin{tabular}{|c|c|c|c|c|c|c|}
\hline \multirow[t]{3}{*}{ Outcomes } & \multicolumn{2}{|c|}{ Illustrative comparative risks ${ }^{*}(95 \% \mathrm{Cl})$} & \multirow{3}{*}{$\begin{array}{l}\text { Relative effect } \\
(95 \% \mathrm{Cl})\end{array}$} & \multirow{3}{*}{$\begin{array}{l}\text { No of Participants } \\
\text { (studies) }\end{array}$} & \multirow{3}{*}{$\begin{array}{l}\text { Quality of the evidence } \\
\text { (GRADE) }\end{array}$} & \multirow[t]{3}{*}{ Comments } \\
\hline & Assumed risk & Corresponding risk & & & & \\
\hline & Control & Vitamin D & & & & \\
\hline \multirow[t]{4}{*}{ Clinical cure rates } & \multicolumn{2}{|c|}{ Study population } & \multirow{4}{*}{$\begin{array}{l}\text { RR } 1.01 \\
(0.91 \text { to } 1.13)\end{array}$} & \multirow{4}{*}{$\begin{array}{l}200 \\
(1 \text { study) }\end{array}$} & \multirow{4}{*}{$\begin{array}{l}\oplus \oplus \Theta \Theta \\
\text { low }^{1,2}\end{array}$} & \\
\hline & 860 per 1000 & $\begin{array}{l}869 \text { per } 1000 \\
(783 \text { to } 972) \\
\end{array}$ & & & & \\
\hline & Moderate & & & & & \\
\hline & 860 per 1000 & $\begin{array}{l}869 \text { per } 1000 \\
(783 \text { to } 972) \\
\end{array}$ & & & & \\
\hline \multirow[t]{4}{*}{ All cause mortality } & \multicolumn{2}{|c|}{ Study population } & \multirow{4}{*}{$\begin{array}{l}\text { RR } 1.01 \\
-(0.23 \text { to } 4.41)\end{array}$} & \multirow{4}{*}{$\begin{array}{l}977 \\
\text { (3 studies) }\end{array}$} & \multirow{4}{*}{$\begin{array}{l}\oplus \oplus \Theta \Theta \\
\text { low }^{3}\end{array}$} & \\
\hline & 6 per 1000 & $\begin{array}{l}6 \text { per } 1000 \\
(1 \text { to } 27)\end{array}$ & & & & \\
\hline & \multicolumn{2}{|l|}{ Moderate } & & & & \\
\hline & 7 per 1000 & $\begin{array}{l}7 \text { per } 1000 \\
(2 \text { to } 31)\end{array}$ & & & & \\
\hline
\end{tabular}

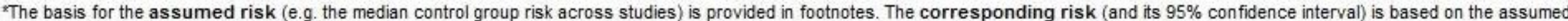
risk in the comparison group and the relative effect of the intervention (and its $95 \% \mathrm{Cl}$ ).

Cl: Confidence interval; RR: Risk ratio;

GRADE Working Group grades of evidence

High quality: Further research is very unlikely to change our confidence in the estimate of effect.

Moderate quality: Further research is likely to have an important impact on our confidence in the estimate of effect and may change the estimate.

Low quality: Further research is very likely to have an important impact on our confidence in the estimate of effect and is likely to change the estimate.

Very low quality: We are very uncertain about the estimate.

${ }^{1}$ Down graded for serious risk of bias because of high risk of attrition bias in study.

${ }^{2}$ Downgraded for serious imprecision because total number of events is less than 300

${ }^{3}$ Downgraded for serious imprecision since there is wide confidence interval from 0.25 to 9.17 
Though identification of aetiological agents is not imperative for the clinical management of pneumonia, trials should try to identify causative respiratory pathogens to evaluate if there is a differential effect of vitamin D on pneumonia due to different causative microbial organisms.

There are large differences between the included and ongoing trials (Tables 1 and $\mathbf{2}$ ) in the dose and regimen of vitamin $D$ being used, ranging from $1000 \mathrm{IU}$ daily to a single dose of 100,000 IU, and some trials have used age-dependent dosing too. There is however a trend in more recent trial designs to use a higher dosage of vita$\min \mathrm{D}$. There is however a need to understand which dose and regimen of vitamin $D$ might have immunomodulatory functions with respect to CAP in infants and children. Future studies should also consider evaluating the underlying vitamin $D$ deficiency status of the populations and quantify the amount of improvement in 25hydroxyvitamin $\mathrm{D}$ level as a result of the intervention. The 2016 Indian tria|[ ${ }^{[24]}$ shows that although the proportion of vitamin $D$ deficient children declined, there was no significant effect on serum levels of immune system mediators like cathelicidin, $\lg G$ and $\lg A$, probably demonstrating that the high dose used did not clearly show any immunomodulatory effects. Use of even higher doses might be limited by safety concerns particularly for a disease like CAP where measurement of serum levels of vitamin $D$ for monitoring in a clinical setting would have resource implications in low- and middle-income countries.

VDR polymorphisms have been shown to affect outcomes in a trial evaluating high dose vitamin $\mathrm{D}$ as an adjunct to tuberculosis treatment. ${ }^{[29]}$ Hence future trials on vitamin $D$ as an adjunct to pneumonia treatment should also investigate the effect of host gene polymorphisms related to the vitamin $D$ mediated immune respons ${ }^{[10]}$ particularly VDR, vitamin $D$ binding protein and CYP27B1 polymorphisms. Future trials should also standardise their definition and measurement of outcomes as well as their dosage and duration of intervention to ensure effective comparisons and adaptability across countries and settings. This is particularly important in terms of the eligibility criteria wherein the definitions of pneumonia and severe pneumonia are used in a uniform manner across studies to allow more meaningful comparison. We found that different trials have used different definitions for this purpose. As a standard the WHO recommended definitions should be used. ${ }^{[30]}$

\section{Conclusion}

Vitamin $D$ is cheap and has the theoretical potential to improve childhood mortality and morbidity due to CAP via its immunomodulatory effects. The role of vitamin $D$ is also being investigated for other infectious diseases like tuberculosis, diarrhoea and malaria. ${ }^{[9][10][33][32][33]}$ Currently however there is no evidence to support the use of vitamin $D$ as an adjunctive treatment for CAP in under-five children in low and middle-income countries, where mortality due to CAP is highest. More research is needed to understand whether vitamin $D$ might have any effect on outcomes for specific aetiologies of CAP, genetic groups, or nutritional groups or at other doses and regimens or outcomes related to radiological resolution of pneumonia on which no data is currently available.

\section{Acknowledgements}

Conflict of Interest: none declared.

Funding: none declared.

\section{References}

1. Walker $\mathrm{CL}$, Rudan I, Liu L, Nair H, Theodoratou E, Bhutta ZA, O'Brien $\mathrm{KL}$, Campbell H, Black RE (2013). "Global burden of childhood pneumonia and diarrhoea". Lancet 381 (9875): 1405-16. doi:10.1016/S01406736(13)60222-6. PMID 23582727.

2. UNICEF. One is too many: ending child deaths from pneumonia and diarrhoea. New York: UNICEF 2016 November. Available online at https://www.unicef.org/lac/20161111_UNICEF-one-is-too-manyreport.pdf (Last retrieved on 18 February 2017)

3. Schlaudecker EP, Steinhoff MC, Moore SR (2011). "Interactions of diarrhea, pneumonia, and malnutrition in childhood: recent evidence from developing countries". Curr. Opin. Infect. Dis. 24 (5): 496-502. doi:10.1097/QCO.0b013e328349287d. PMID 21734569. PMC 5454480.

4. Nnoaham KE, Clarke A (2008). "Low serum vitamin D levels and tuberculosis: a systematic review and meta-analysis". Int J Epidemiol 37 (1): 113-9. doi:10.1093/ije/dym247. PMID 18245055.

5. Berry DJ, Hesketh K, Power C, Hyppönen E (2011). "Vitamin D status has a linear association with seasonal infections and lung function in British adults". Br. J. Nutr. 106 (9): 1433-40. doi:10.1017/S0007114511001991. PMID 21736791.

6. Quraishi SA, Bittner EA, Christopher KB, Camargo CA (2013). "Vitamin D status and community-acquired pneumonia: results from the third National Health and Nutrition Examination Survey". PLOS ONE 8 (11): e81120. doi:10.1371/journal.pone.0081120. PMID 24260547. PMC 3829945.

7. Laaksi I, Ruohola JP, Tuohimaa P, Auvinen A, Haataja R, Pihlajamäki H, Ylikomi T (2007). "An association of serum vitamin $D$ concentrations $<40$ $\mathrm{nmol} / \mathrm{L}$ with acute respiratory tract infection in young Finnish men". Am. J. Clin. Nutr. 86 (3): 714-7. PMID 17823437.

8. Barbour GL, Coburn JW, Slatopolsky E, Norman AW, Horst RL (1981). "Hypercalcemia in an anephric patient with sarcoidosis: evidence for extrarenal generation of 1,25-dihydroxyvitamin D". N. Engl. J. Med. 305 (8): 440-3. doi:10.1056/NEJM198108203050807. PMID 6894783.

9. Chun RF, Adams JS, Hewison M (2011). "Immunomodulation by vitamin D: implications for TB". Expert Rev Clin Pharmacol 4 (5): 583-91. doi:10.1586/ecp.11.41. PMID 22046197. PMC 3201845.

10. Charan J, Goyal JP, Saxena D, Yadav P (2012). "Vitamin D for prevention of respiratory tract infections: A systematic review and meta-analysis". J Pharmacol Pharmacother 3 (4): 300-3. doi:10.4103/0976-500X.103685. PMID 23326099. PMC 3543548.

11. Bergman $P$, Lindh AU, Björkhem-Bergman L, Lindh JD (2013). "Vitamin D and Respiratory Tract Infections: A Systematic Review and Meta-Analysis 
of Randomized Controlled Trials". PLOS ONE8 (6): e65835. doi:10.1371/journal.pone.0065835. PMID 23840373. PMC 3686844.

12. Martineau $A R$, Jolliffe $D A$, Hooper $R L$, Greenberg $L$, Aloia JF, Bergman $P$, Dubnov-Raz G, Esposito S, Ganmaa D, Ginde AA, Goodall EC, Grant CC, Griffiths CJ, Janssens W, Laaksi I, Manaseki-Holland S, Mauger D, Murdoch DR, Neale R, Rees JR, Simpson S, Stelmach I, Kumar GT, Urashima M, Camargo CA (2017). "Vitamin D supplementation to prevent acute respiratory tract infections: systematic review and meta-analysis of individual participant data". BMJ 356: i6583. PMID 28202713. PMC 5310969.

13. "Association of subclinical vitamin $D$ deficiency with severe acute lower respiratory infection in Indian children under 5 y". Eur J Clin Nutr 58 (4): 563-7. 2004. doi:10.1038/sj.ejcn.1601845. PMID 15042122.

14. Pletz MW, Terkamp C, Schumacher U, Rohde G, Schütte H, Welte T, Bals $R$ (2014). "Vitamin D deficiency in community-acquired pneumonia: low levels of 1,25(OH)2 D are associated with disease severity". Respir. Res. 15: 53. doi:10.1186/1465-9921-15-53. PMID 24766747. PMC 4046524.

15. Salimpour R (1975). "Rickets in Tehran. Study of 200 cases". Arch. Dis. Child. 50 (1): 63-6. PMID 1124945. PMC 1544491.

16. Rehman PK (1994). "Sub-clinical rickets and recurrent infection". J. Trop. Pediatr. 40 (1): 58. PMID 8182788.

17. Muhe L, Lulseged S, Mason KE, Simoes EA (1997). "Case-control study of the role of nutritional rickets in the risk of developing pneumonia in Ethiopian children". Lancet 349 (9068): 1801-4. doi:10.1016/S01406736(96)12098-5. PMID 9269215.

18. Moher D, Liberati A, Tetzlaff J, Altman DG (2009). "Preferred reporting items for systematic reviews and meta-analyses: the PRISMA statement". Ann. Intern. Med. 151 (4): 264-9, W64. PMID 19622511.

19. World Health Organization. Acute respiratory infections in children: case management in small hospitals in developing countries. WHO/ARI/90.5 1990

20. Higgins JPT, Green S (editors). Cochrane Handbook for Systematic Reviews of Interventions Version 5.1.0 [updated March 2011]. The Cochrane Collaboration, 2011. Available from http://www.cochranehandbook.org.

21. The Nordic Cochrane Centre, The Cochrane Collaboration. Review Manager (RevMan). 5.2. Copenhagen: The Nordic Cochrane Centre, The Cochrane Collaboration, 2012.

22. Guyatt GH, Oxman AD, Vist GE, Kunz R, Falck-Ytter Y, Alonso-Coello P, Schünemann HJ (2008). "GRADE: an emerging consensus on rating quality of evidence and strength of recommendations". BMJ 336 (7650): 924-6. doi:10.1136/bmj.39489.470347.AD. PMID 18436948. PMC 2335261.

23. Choudhary N, Gupta P (2012). "Vitamin D supplementation for severe pneumonia--a randomized controlled trial". Indian Pediatr 49 (6): 449-54. PMID 21992858.

24. Gupta P, Dewan P, Shah D, Sharma N, Bedi N, Kaur IR, Bansal AK, Madhu SV (2016). "Vitamin D Supplementation for Treatment and Prevention of
Pneumonia in Under-five Children: A Randomized Double-blind Placebo Controlled Trial". Indian Pediatr 53 (11): 967-976. PMID 27889723.

25. Manaseki-Holland S, Qader G, Isaq Masher M, Bruce J, Zulf Mughal M, Chandramohan D, Walraven G (2010). "Effects of vitamin D supplementation to children diagnosed with pneumonia in Kabul: a randomised controlled trial". Trop. Med. Int. Health 15 (10): 1148-55. doi:10.1111/j.1365-3156.2010.02578.x. PMID 20723187.

26. Yakoob MY, Salam RA, Khan FR, Bhutta ZA (2016). "Vitamin D supplementation for preventing infections in children under five years of age". Cochrane Database Syst Rev 11: CD008824. doi:10.1002/14651858.CD008824.pub2. PMID 27826955. PMC 5450876.

27. Binks MJ, Smith-Vaughan HC, Bar-Zeev N, Chang AB, Andrews RM (2014). "Vitamin D insufficiency among hospitalised children in the Northern Territory". J Paediatr Child Health 50 (7): 512-8. doi:10.1111/jpc.12623. PMID 24943250.

28. Remmelts HH, van de Garde EM, Meijvis SC, Peelen EL, Damoiseaux JG, Grutters JC, Biesma DH, Bos WJ, Rijkers GT (2012). "Addition of vitamin D status to prognostic scores improves the prediction of outcome in community-acquired pneumonia". Clin. Infect. Dis. 55 (11): 1488-94. doi:10.1093/cid/cis751. PMID 22942205.

29. Martineau AR, Timms PM, Bothamley GH, Hanifa Y, Islam K, Claxton AP, Packe GE, Moore-Gillon JC, Darmalingam M, Davidson RN, Milburn HJ, Baker LV, Barker RD, Woodward NJ, Venton TR, Barnes KE, Mullett CJ, Coussens AK, Rutterford CM, Mein CA, Davies GR, Wilkinson RJ, Nikolayevskyy V, Drobniewski FA, Eldridge SM, Griffiths CJ (2011). "Highdose vitamin $D(3)$ during intensive-phase antimicrobial treatment of pulmonary tuberculosis: a double-blind randomised controlled trial". Lancet 377 (9761): 242-50. doi:10.1016/S0140-6736(10)61889-2. PMID 21215445. PMC 4176755.

30. WHO Pocket Book. Pocket Book of Hospital care for children: Guideline for the Management of Common Childhood Illness- 2nd ed. [Internet]. 2nd Edition. 2013. 1-412 p.

31. Borella E, Nesher G, Israeli E, Shoenfeld Y (2014). "Vitamin D: a new antiinfective agent?". Ann. N. Y. Acad. Sci. 1317: 76-83. doi:10.1111/nyas.12321. PMID 24593793

32. Aluisio AR, Maroof Z, Chandramohan D, Bruce J, Mughal MZ, Bhutta Z, Walraven G, Masher MI, Ensink JH, Manaseki-Holland S (2013). "Vitamin $D_{3}$ supplementation and childhood diarrhea: a randomized controlled trial". Pediatrics 132 (4): e832-40. doi:10.1542/peds.2012-3986. PMID 24019420. PMC 3866796.

33. He X, Yan J, Zhu X, Wang O, Pang W, Qi Z, Wang M, Luo E, Parker DM, Cantorna MT, Cui L, Cao Y (2014). "Vitamin D inhibits the occurrence of experimental cerebral malaria in mice by suppressing the host inflammatory response". J. Immunol. 193 (3): 1314-23. doi:10.4049/jimmunol.1400089. PMID 24965778. PMC 4110641. 